\title{
La Guerra Civil española y su impacto en la prensa vasca de América: el caso del periódico Euzko Deya de Buenos Aires
}

Nadia Andrea De Cristóforis

Universidad de Buenos Aires (IHE - IIGG), Universidad Nacional de Luján, Consejo Nacional de Investigaciones Científicas y Técnicas, Argentina

Fecha de recepción: 15 de abril de 2020. Fecha de aceptación: 8 de junio de 2020.

\section{Resumen}

La corriente de exiliados vascos que llegó a la Argentina a partir de la Guerra Civil española contribuyó a politizar muchos órganos de prensa comunitarios ya existentes en dicho país y también impulsó la creación de un periódico de gran peso propagandístico y cultural: Euzko Deya de Buenos Aires. Esta último se propuso defender la causa del nacionalismo vasco en el continente americano, así como ayudar a los exiliados vascos que buscaban desplazarse desde Europa hacia la Argentina. En el presente artículo intentaremos analizar los rasgos principales de esta publicación en los primeros años de su existencia, con el fin de avanzar en posteriores trabajos en un estudio comparativo más amplio sobre la prensa española en Buenos Aires durante la Guerra Civil y el primer franquismo. Para ello, atenderemos a sus contenidos, representaciones, imágenes y finalidades, tomando en cuenta que dicho periódico no solo se dirigió a un público vasco y sus descendientes, sino también a interlocutores locales más amplios, en América y Europa.

Palabras clave: Buenos Aires, Exilio, Guerra Civil española, Prensa, Vascos. 
The Spanish Civil War and its impact on the Basque press of America: the case of the newspaper Euzko Deya of Buenos Aires $^{1}$

\begin{abstract}
The flow of Basque exiles who arrived in Argentina from the Spanish Civil War contributed to politicizing many community press bodies already in that country and also spurred the creation of a newspaper of great propaganda and cultural weight: Euzko Deya of Buenos Aires. The latter set out to defend the cause of Basque nationalism in the Americas, as well as to help Basque exiles seeking to move from Europe to Argentina. In this article we will try to analyze the main features of this publication in the first years of its existence, in order to advance further work in a broader comparative study on the Spanish press in Buenos Aires during the Civil War and the first Francoism. To this end, we will attend to its contents, representations, images and purposes, taking into account that this newspaper was addressed not only to a Basque audience and its descendants, but also to wider local partners, in America and Europe.
\end{abstract}

Keywords: Buenos Aires, Exile, Spanish Civil War, Press, Basques.

\title{
Introducción
}

A comienzos del siglo XX la comunidad española en la Argentina ocupaba un destacado lugar, constituyéndose en el segundo grupo europeo en términos numéricos, luego de los italianos. ${ }^{2}$ La inmigración hispánica, con una larga tradición que se remontaba a la etapa de dominación colonial, tendió a localizarse predominantemente en las áreas ligadas al desarrollo agroexportador de fines del siglo XIX y comienzos del XX, alcanzando altos índices de concentración en las ciudades, especialmente en Buenos Aires. ${ }^{3}$ Dentro de esta última el colectivo hispánico exhibía una importante diversidad regional: no solo el aporte humano cuantitativo de cada región española había sido dispar, sino que también cada grupo regional

2 Según el Tercer Censo Nacional de 1914, en este año los españoles de ambos sexos alcanzaban a las 829.701 personas, mientras que los italianos, a las 929.863 (Tercer Censo Nacional, 1916: 397).

3 Según el Censo de Buenos Aires de 1936, el número de peninsulares instalados en la capital argentina llegaba a las 324.650 personas de ambos sexos en dicho año (Cuarto Censo General..., 1936: 16). 
presentaba rasgos idiosincráticos y formas de integración particulares dentro de la sociedad de acogida.

Resulta difícil precisar la dimensión numérica de cada grupo regional peninsular dentro de la capital argentina en el primer tercio del siglo XX, por las lagunas existentes en la documentación disponible, pero algunos cálculos estimativos, basados en fuentes indirectas, arrojan algunas cifras tentativas para la etapa 1900-1910, que sugieren que los gallegos eran predominantes (alcanzando alrededor del 48\% del total), seguidos por los castellanos (10\%), catalanes (9\%), andaluces (8\%), vascos y asturianos (cada uno de estos grupos representando el $7 \%$ del total). ${ }^{4}$

Los vascos formaron parte de las corrientes inmigratorias "tempranas" en el país austral: incrementaron sus llegadas al mismo a fines de la etapa colonial y luego de las guerras de independencia y civiles que tuvieron lugar en el área rioplatense. Su presencia en los ámbitos rurales bonaerenses fue importante desde la década de 1840, acompañando la expansión del ciclo de la cría de ganado lanar, y se incrementó en las décadas de 1860 y 1870, al aprovechar las oportunidades laborales de todo tipo que se abrían en áreas de la frontera sur de la provincia de Buenos Aires (Irianni, 2010: 113-155). Esta localización más bien rural constituyó un rasgo distintivo de la inmigración vasca temprana, aunque las corrientes migratorias posteriores (entre 1880 y 1930) se dirigieron en números crecientes a algunas ciudades, como Buenos Aires, Mar del Plata, Rosario, La Plata o Bahía Blanca, entre otras.

Para la tercera década del siglo XX los vascos, como los otros grupos regionales españoles, poseían en la Argentina una amplia gama de instituciones, que iban desde los centros culturales-recreativos -como el Laurat Bak de Buenos Aires, fundado en 1877-, hasta los benéfico-educativos -como el Euskal Echea de Lavallol, que se comenzó a construir en 1904-. También habían creado no menos de cinco iniciativas periodísticas, de las cuales la decana, la revista La Baskonia, remontaba sus orígenes a 1893 (Bergareche, 2009; Cruset, 2011: 124-125; Sanz Goikoetxea y Álvarez Gila, 2010a: 205).

A partir del inicio de la Guerra Civil española, y más aún a partir de los meses finales de dicha contienda, una importante corriente de exiliados vascos se dirigió a Buenos Aires, contribuyendo a politizar muchos de los órganos de prensa comunitarios ya existentes, o impulsando la creación

4 Estos cálculos de Moya (2004: 28) están basados en las fichas de inscripción de todos los españoles que se unieron a la Asociación de Socorros Mutuos de Buenos Aires durante la mencionada década. 
de uno nuevo que tendría un importante impacto dentro de la comunidad vasca emigrada en Sudamérica: el Euzko Deya de Buenos Aires (Álvarez Gila, 2019: 21-22).

Euzko Deya. La voz de los vascos en América (en adelante, Euzko Deya) nació el 10 de mayo de 1939 y se propuso defender la causa del nacionalismo vasco y de los exiliados del País Vasco, muchos de ellos encarcelados o en situación crítica en Francia. El citado órgano de prensa tuvo una prolongada edición hasta 1987, con una frecuencia decenal desde su origen hasta junio de 1950, quincenal de julio de 1950 a diciembre de 1951, y mensual de enero de 1952 en adelante. En el presente artículo intentaremos analizar los rasgos principales de esta publicación en los primeros años de su existencia, con el fin de avanzar en posteriores trabajos en un estudio comparativo más amplio de la prensa española en Buenos Aires, durante la Guerra Civil y el primer franquismo. ${ }^{5}$ Para ello, atenderemos a sus contenidos, representaciones, imágenes y finalidades, tomando en cuenta que dicho periódico no solo se dirigió a un público vasco y sus descendientes, sino también a interlocutores locales más amplios, en América y Europa.

Los estudios que poseemos hasta el momento sobre órganos de prensa españoles de índole regional en la Argentina, en la etapa de la Guerra Civil y posterior franquismo, se han concentrado predominantemente en los de la comunidad catalana y gallega (como por ejemplo: Ressorgiment y Catalunya de los catalanes -Fernández, 2010, 2019; Lucci, 2020-, o Correo de Galicia, Fe Gallega y Galicia, de los gallegos -De Cristóforis, 2019; Fasano, 2010, 2014-), dejando en un segundo plano los de la vasca. Los periódicos de este último colectivo en Buenos Aires, que han recibido una destacada atención en períodos previos a 1936 (véase entre otros: Álvarez Gila, 2019; Bergareche, 2009), han sido poco indagados en la etapa de la Guerra Civil y del régimen de Franco, a excepción de un par de análisis sobre el Euzko Deya de Buenos Aires y de México D. F. (Chueca Intxusta, 2011; Mota Zurdo, 2018), que han sido elaborados desde perspectivas y preguntas diferentes a las del presente artículo. En este sentido, esperamos también que la exploración presentada en este trabajo contribuya a aportar nuevos elementos a un campo de estudio que amerita aún más indagaciones.

5 Gracias al proyecto Urazandi Digital, iniciativa de la Dirección para los Ciudadanos y las Colectividades Vascas en el exterior del Gobierno Vasco, se puede consultar una versión digital de Euzko Deya. La voz de los vascos en América en https://urazandidigital.euskaletxeak.eus/ 


\section{Un periódico institucional surgido con fines políticos}

Dominado el País Vasco por las fuerzas franquistas desde mediados de 1937 y trasladado el gobierno de José Antonio Aguirre a Barcelona, este último comenzó a concebir al continente americano como un ámbito de acción de su política exterior, y más concretamente, como espacio de destino para las corrientes de exiliados que hallaban dificultades para permanecer en Francia. Siguiendo la política mantenida en Europa, donde el Gobierno Vasco había creado distintas Delegaciones representativas, en el continente americano también se propuso organizar instituciones de este tipo. Estas últimas tuvieron como finalidades principales difundir una imagen del País Vasco opuesta a la que estaban propagando las fuerzas nacionales, y establecer una red de apoyos para acoger a los exiliados vascos que se encontraban refugiados en diferentes destinos, pero principalmente en Francia (Sanz Goikoetxea y Álvarez Gila, 2010a: 158-159).

La Delegación de Buenos Aires nació en noviembre de 1938 y estaría destinada a ser una de las más importantes del continente americano. En la ciudad porteña las instituciones vascas estaban informadas de los avatares de la política en el País Vasco, reaccionaban frecuentemente frente a los debates y polémicas que allí surgían y habían seguido atentamente el derrotero de la Guerra Civil española en su tierra natal. Constituían un tejido institucional apto para apoyar las iniciativas de la Delegación en Buenos Aires (Sanz Goikoetxea y Álvarez Gila, 2010a: 205-206). Esta última impulsó la creación de Euzko Deya en la ciudad porteña, publicación que se uniría a sus homónimas de París (1936), Londres (1938) y más tarde, México D. F. (1943), como voz oficial del Gobierno Vasco en el exilio (Mota Zurdo, 2018).

La Euzko Deya de París surgió el 29 de noviembre de 1936, se editaba en francés, español y euskera, e iba dirigida a los franceses, pero principalmente a los exiliados vascos que en crecientes números buscaban refugio en el país galo por vía terrestre o marítima. Como sostuvo Chueca Inxusta (2011: §2), la publicación pionera Euzko Deya de París marcó y condicionó los grandes ejes temáticos que luego retomarían las cabeceras de Euzko Deya fundadas en la ciudad de Buenos Aires y México D. F., ligados a los ecos y reflejos de la Guerra Civil española. Esos ejes temáticos principales fueron los siguientes: 1) la reactivación de la memoria histórica reciente en torno a ciertos acontecimientos convertidos en símbolos u objeto de controversia, como los bombardeos en Durango o en Guernika, en 1937; 2) el proceso de construcción de la nación vasca, que culminó en la aprobación del Estatuto de Autonomía y en la constitución del Gobierno Vasco, ya en plena contienda; 3) la dimensión internacional de la Guerra Civil, como 
consecuencia de la participación de las fuerzas alemanas e italianas en las ofensivas dentro del País Vasco; 4) la reivindicación de las víctimas de la guerra, haciendo hincapié en la contradicción involucrada en las acciones represivas contra sacerdotes o sectores confesionalmente católicos, desarrolladas por los nacionales en nombre de una "Cruzada" cristiana y la religión católica (Chueca Inxusta, 2011: $\S \S 8-20$ ).

La fundación del periódico Euzko Deya en Buenos Aires tuvo un carácter pionero dentro del continente americano. Consideramos que surgió en dicha ciudad condicionado por distintos factores: la presencia de una importante comunidad vasca emigrada con una larga tradición histórica y con un destacado desarrollo societario, como ya comentamos; el arraigo del nacionalismo vasco en la capital porteña para fines de la década de 1930, especialmente en los centros vascos más representativos del movimiento asociativo de la comunidad; la actitud favorable del gobierno argentino de Roberto Ortiz hacia la recepción de los exiliados vascos, cuestión que se traduciría en la sanción de dos decretos (del 20/01/1940 y del 18/07/1940) que promovían su llegada al país; y la existencia de un grupo de exiliados vascos que acrecentó su número especialmente desde 1938-1939, al compás de la dificultades existentes para encontrar refugio en Francia o permanecer en dicho país (Alonso Carballés, 2007: 700). Tengamos presente que, según las estimaciones de Schwarzstein (2001: 83-84), dentro de la Argentina los exiliados vascos constituyeron numéricamente el segundo grupo de refugiados peninsulares, desde un punto de vista regional, luego de los catalanes, representando aproximadamente el 16,7\% del exilio español en la nación sudamericana. ${ }^{6} \mathrm{Si}$ bien la Argentina no mantuvo en líneas generales políticas proclives a la llegada de los refugiados españoles, muchos de ellos lograron arribar a la misma a través de las redes conformadas por familiares y paisanos, quienes facilitaron de distinta forma su traslado e inserción en la sociedad receptora. Incluso a partir de la sanción de los decretos mencionados el Comité Pro-Inmigración Vasca, sobre el que volveremos más adelante, estuvo en condiciones de favorecer la entrada de dichos exiliados (De Cristóforis y Cócaro, 2011; Schwarzstein, 2001: 72-78). Tanto los refugiados vascos como los antiguos inmigrantes de dicha procedencia constituyeron el público privilegiado a ser captado por Euzko Deya.

Dicho órgano de difusión fue dirigido hasta 1946 por Ramón María Aldasoro Galarza, quien le otorgaría un halo institucional, y no tan nacionalista al mismo, dado que era quien conducía la Delegación vasca en Buenos Aires y además, era consejero del Gobierno Vasco por Izquierda Republicana (Mota 
Zurdo, 2018: 111). Además, en Euzko Deya participaron como colaboradores algunos emigrados vascos llegados antes del desencadenamiento de la Guerra Civil (Juan León Cruzalegui, Gabino Garriga, entre otros), así como exiliados que huyeron de la represión franquista desde España o Francia, entre 1938 y 1939 (como Isaac López Mendizábal -con los seudónimos de "Ixaca” o "Aitona”-, Pablo Archanco, Santiago Cunchillos, Víctor Ruiz Añibarro "Errea”, Andrés Irujo "Arrazil” o "Lizarra”, Andoni Astigarraga “Astilarra”, José Olivares Larrondo “Tellagorri”, Ildefonso Gurrutxaga, entre otros) (Chueca Inxusta, 2011: §5).

Pese a ser un órgano de carácter institucional, Euzko Deya no era financiado por la Delegación del Gobierno Vasco en Buenos Aires, sino mediante suscripciones y avisos publicitarios. Las primeras tenían un valor de $\$$ 1,50 m. n. por trimestre, y se abonaban en la sede de redacción y administración del periódico, en San Martín 640, escritorio 22, de la ciudad porteña (sede que a partir de septiembre de 1939 se trasladó a Florida 461, escritorio 9). No siempre lo recaudado a través de estas vías alcanzó para cubrir todos los gastos involucrados en la publicación. En los primeros meses de 1941, por ejemplo, se llegaron a comunicar en sus páginas las dificultades financieras por las que atravesaba, solicitándose el apoyo económico de los vascos instalados en la Argentina para garantizar la continuidad de las ediciones.

En su primer número, Euzko Deya se presentaba como un periódico dirigido a los vascos residentes en la América del Sur y a todos los "hombres de buena voluntad" que pudieran tener interés en Euskadi ("Con la boina en la mano", 1939: 1). En su Editorial inicial explicaba que había surgido a causa de la penosa situación en la que había quedado el País Vasco luego de la Guerra Civil (“Con la boina en la mano”, 1939: 1). Para el órgano de prensa en consideración los problemas fundamentales que había acarreado la contienda consistían en la desaparición física de toda una generación de jóvenes combatientes, el surgimiento de una corriente de exiliados hacia Francia y el continente americano, las pérdidas humanas entre la población civil, los funestos resultados de la represión franquista -con vascos encerrados en prisiones o en campos de concentración-, el destrozo material de pueblos enteros y la crisis económica dominante. En este sombrío panorama la vida de Euskadi se encontraba trastocada y quebrantada. Por ello, y frente a esta tragedia, Euzko Deya pedía el apoyo moral de los pueblos de la América del Sur, afirmando:

Euskadi quiere vivir, reorganizar su vida. No ha merecido esto. No ha provocado directa o indirectamente la guerra. Nos hemos defendido en ella con nuestras propias fuerzas y a costa de ríos de sangre y de 
Ilantos. La hemos perdido militarmente. Pero no nos resignamos a morir. Ni siquiera tenemos derecho a ello. [...]

Trataremos de reconstruir nuestra vida rota por la maldita máquina de la guerra. Os hablaremos de Euskadi, de su historia, de sus costumbres, de sus esfuerzos, de su lengua, de su arte, de su pasado y de su presente luctuoso, con una preocupación reconstructiva por norma firme y fija ("Con la boina en la mano", 1939: 2).

Desde un comienzo, Euzko Deya se preocupó por dar a conocer las noticias específicas que tenían que ver con las organizaciones y acciones de solidaridad con los vascos exiliados. Por ejemplo, las emakumes, a las que nos referiremos más adelante, o la "Liga Internacional de Amigos de los Vascos",7 que inauguró una sección sudamericana en la ciudad de Buenos Aires (en Florida al 461, escritorios 4-9). Dicha sección, denominada "Liga de los Amigos de los Vascos", difundió sus finalidades en Euzko Deya y a su vez se valió de este medio para concitar adhesiones. Sus objetivos principales estuvieron ligados al auxilio de los exiliados (liberar a los encarcelados y asistir a los que buscaban trasladarse al continente americano) y al socorro de los niños huérfanos y abandonados ("Liga de los Amigos...", 1939: 8; "Llamamiento a los vascos...”, 1939: 8).

A los pocos números de su aparición, Euzko Deya alentaba a sus lectores a comprometerse con la tarea de reivindicación del pueblo vasco, en especial, frente a la imagen del mismo que había difundido la propaganda franquista, asociándolo a la anarquía y la falta de religión ("Reafirmación...", 1939: 2). El periódico esperaba que esta tarea pudiera ser realizada por los vascos establecidos en distintos puntos del continente americano, a quienes buscaba persuadir. De hecho, el Euzko Deya de Buenos Aires llegó a difundirse en diferentes países americanos y contó con corresponsales en Uruguay, Chile, Perú, Colombia, Cuba, República Dominicana, Estados Unidos y Venezuela, entre otros destinos (Mota Zurdo, 2018: 111). Estos corresponsales transmitieron importantes informaciones sobre la situación socio-cultural de las comunidades vascas asentadas en dichos países, especialmente, noticias sobre las entidades politizadas por la inserción de exiliados vascos nacionalistas dentro de las mismas. Como afirmó Mota Zurdo (2018: 112), tanto Euzko Deya de Buenos Aires, como más tarde su homónima de México D.

7 Dicha Liga, fundada el 16 de diciembre de 1938 por el Gobierno Vasco en el exilio en París, con la colaboración de la Delegación vasca en dicha ciudad, estuvo destinada a oficiar de portavoz de los derechos de los vascos ante los gobiernos y la opinión pública de todo el mundo. Quedó conformada por dos grupos de acción: el "Comité de Ayuda a los Vascos" (encargado de proveer a los refugiados de ayuda material) y el "Comité de Intereses Generales de Euskadi" (abocado a la propaganda y difusión internacional de la causa) (Sanz Goikoetxea y Álvarez Gila, 2010b: 107-108). 
F., brindaron una imagen parcial de las instituciones vascas en América, haciendo hincapié en el desenvolvimiento de las afines al nacionalismo vasco y omitiendo, o dejando en un plano muy secundario, a aquellas que defendían los principios del socialismo, anarquismo o comunismo.

\section{Las vinculaciones con la sociedad argentina}

La concentración en los problemas y necesidades del pueblo vasco, no implicó que Euzko Deya desdeñara sus relaciones con miembros de la sociedad argentina, sino todo lo contrario: los promotores del periódico se propusieron iniciar o reforzar distintos lazos con ellos, convirtiéndolos en interlocutores válidos para canalizar sus demandas y discursos.

Ya en su primer número, Euzko Deya expresaba su respeto y admiración hacia el presidente de la Argentina Roberto Marcelino Ortiz, concibiéndolo como la encarnación de las instituciones democráticas del país sudamericano y como exponente de la descendencia vasca en el Río de la Plata (recordemos que Ortiz era hijo de padre vizcaíno y de madre navarra).

Las relaciones con sectores intelectuales y políticos de distintas partes de la Argentina no tardarían en ponerse en evidencia en Euzko Deya. De este modo, varios de sus artículos se dedicaron a manifestar el interés de periódicos o dirigencias de algunas localidades o ciudades del país austral, por la situación del pueblo vasco en el exilio. Por ejemplo, se daba cuenta de cómo un periódico de Bahía Blanca, titulado El Atlántico, había comenzado a publicar todos los domingos noticias sobre el País Vasco, con el fin de transmitir cuáles eran sus problemas y sensibilizar al público lector sobre sus necesidades (“`El Atlántico’ de Bahía Blanca”, 1939: 8).

Pero la articulación más fuerte que Euzko Deya logró con la sociedad argentina fue a través de su propósito de promover la llegada al país austral de los exiliados vascos que se encontraban en Francia. Para ello, actuó como vocero del Comité Pro-Inmigración Vasca en la Argentina, un organismo que se constituyó el 30 de agosto de 1939, bajo la presidencia del ingeniero José Urbano Aguirre, con el objeto de gestionar ante el Poder Ejecutivo de la Nación Argentina el ingreso de los refugiados vascos al país. El Comité se manifestaba a favor de la llegada de "inmigrantes", cuando en realidad prohijaba el arribo de los exiliados, quienes al ser considerados como “elementos peligrosos” por la legislación migratoria de la época, encontraban numerosos obstáculos burocrático-administrativos para entrar a la Argentina (Devoto, 2001: 287-292). 
La Delegación conducida por Aldasoro Galarza en Buenos Aires intentó controlar sin éxito al Comité Pro-Inmigración Vasca, de allí que terminara focalizándose en la información de sus acciones a través de Euzko Deya. En las páginas de este último se publicaron artículos que apuntaban a fundamentar y legitimar el ingreso de los vascos al país austral (el primero de ellos apareció el 30 de agosto de 1939), así como también se dieron a conocer los comunicados del Comité Pro-Inmigración Vasca en la Argentina, los cuales se dirigían "a los vascos radicados en la Argentina, a los argentinos de estirpe vasca y a todos los que simpaticen con los vascos" "Comité Pro-Inmigración Vasca”, 1939: 5). La difusión de estos anuncios destinados a un amplio público tenía que ver con la necesidad de lograr el mayor consenso posible para el accionar presente y futuro de dicho comité, cuyas importantes facultades quedaron estipuladas finalmente en el Decreto del Presidente Ortiz del 20 de enero de 1940: actuar como garantes de los antecedentes de buena conducta y aptitudes físicas y morales de los vascos residentes en España o en Francia, que desearan trasladarse a la Argentina. Euzko Deya publicó este decreto en su tapa del 20 de enero de 1940, haciéndose eco de las auspiciosas noticias para los exiliados vascos que trataban de encontrar refugio en la Argentina (Euzko Deya, 1940a: 1). También difundió el contenido del segundo decreto del Poder Ejecutivo (del 18 de julio de 1940), que ampliaba lo estipulado en el anterior decreto, al permitir el ingreso de los vascos sin distinción de origen ni de lugar de residencia, y al autorizar al citado comité a intervenir en la regularización de la situación de los pasajeros vascos que ya se encontraban en la Argentina (Euzko Deya, 1940b: 1).

El hecho de que los vascos fueron percibidos desde los círculos políticos e intelectuales argentinos como sujetos muy religiosos y no peligrosos ideológicamente, sumado a la extracción social y prestigio de los miembros del Comité Pro-Inmigración Vasca, son factores que permitirían explicar gran parte del éxito de las gestiones del último organismo (Schwarzstein, 2001: 69 y 71). Algunos sectores de la comunidad española en la Argentina, desde el ex embajador Ángel Ossorio y Gallardo, hasta las dirigencias de otros grupos peninsulares de gran peso cuantitativo en el país austral, como las de la comunidad gallega, expresaron sus reparos ante una decisión que beneficiaba a un grupo hispánico particular y dejaba afuera al resto de los españoles que también necesitaban urgentemente hallar un nuevo lugar de residencia fuera de la Europa en guerra (“Con motivo...”, 1940: 9-10; Schwarzstein, 2001: 74). Los decretos en cuestión también generaron controversias en la opinión pública argentina en general. No obstante ello, las acciones del Comité Pro-Inmigración Vasca dieron algunos resultados positivos: alrededor de 1.400 vascos lograron ingresar al país austral gracias a las gestiones de dicho organismo, justo antes de que las posibilidades de salir de Europa se vieran seriamente limitadas por el avance de las fuerzas alemanas sobre dicho continente. 
La relación de Euzko Deya con la sociedad argentina también se produjo en otros planos más simbólicos, como aquel ligado a la conmemoración de efemérides que signaban el surgimiento y desarrollo de la nación sudamericana, tales como: la sanción de la Constitución Nacional (1/05/1853); la conformación del primer gobierno patrio (25/05/1810); el Acuerdo de San Nicolás (31/o5/1852) ("Efemérides argentinas del mes", 1939: 6); o el Día de la Bandera ("Homenaje a la Bandera", 1939: 1), entre otras. Por ello, Euzko Deya daba a conocer el significado de estas fechas y se sumaba a su celebración, demostrando además de qué modos la "raza vasca" había contribuido con hechos concretos a la construcción de la nación argentina, especialmente a lo largo del siglo XIX. De allí que se publicara la nómina de vascos que habían participado en la gesta de Mayo, en la proclamación de la Independencia en Tucumán, o en los gobiernos provinciales hasta 1880 ("Los vascos en la independencia argentina", 1939: 1).

Euzko Deya también se ocuparía de poner de relieve el pensamiento a favor de los vascos de algunos políticos destacados de la historia argentina, como el presidente Carlos Pellegrini, quien había señalado el peso de los vascos en la conformación de la aristocracia argentina y su importante papel dentro de las emigraciones hacia el país austral ("El presidente Pellegrini...", 1939: 8). Ello permitía evidenciar las simpatías que gozaban los vascos entre la dirigencia local, la que era presentada en Euzko Deya como una constelación de personalidades vinculadas por lazos de sangre con el pueblo vasco.

\section{Los componentes de la identidad vasca según Euzko-Deya}

Para el órgano de prensa en estudio la religión católica era uno de los elementos constitutivos principales de la identidad vasca. En una colaboración con el periódico, Amado Alonso afirmaba que los vascos aspiraban a ser reconocidos por el mundo entero como un pueblo "eminentemente católico”, antes, durante y luego del fin de la Guerra Civil. Según el citado autor, hasta en los mismos campos de concentración para exiliados españoles en Francia, los vascos mantenían las prácticas del culto católico (Alonso, 1939b: 1).

Ese catolicismo había establecido vínculos ambiguos con el comunismo. Euzko Deya se preocupaba por demostrar que los defensores de uno y otro habían sostenido relaciones de colaboración dentro del País Vasco (fundadas en el objetivo de resistir y oponerse a un enemigo en común: las fuerzas nacionales), pero que el primero no estaba aliado con el segundo por otros motivos o cuestiones (“Los Vascos y los Comunistas”, 1939: 2). 
Euzko Deya contribuía a reforzar la identidad vasca como una comunidad de sangre, una raza que poseía determinados atributos (la honradez, la limpieza, la honestidad, la laboriosidad o la austeridad) que no solo eran reconocidos por los mismos vascos, sino también por quienes no lo eran ("Lo que los no vascos piensan de los vascos", 1939: 2). De este modo, esta identidad se construía desde dentro de la comunidad, pero también desde fuera de la misma, y permitía consolidar un nacionalismo cultural que apoyaba y afianzaba la idea de que como pueblo, los vascos tenían derechos propios, que autorizaban a defender su propia autonomía en el marco del Estado español. Esa identidad remitía al espacio español, excluyendo al País Vasco francés.

En el fondo, Euzko Deya expresaba y defendía los fundamentos del nacionalismo vasco, tal como se habían manifestado en la prensa que vehiculizaba dicha ideología en el País Vasco español. Dichos fundamentos eran la raza, la religión, la lengua y la historia. La existencia de una raza se asociaba también a determinadas características fenotípicas de los vascos; la religión con un catolicismo profundo y arraigado en el ámbito vasco de origen y en los de emigración; la lengua -el euskera o vascuence- se definía en su singularidad, pues es una de las pocas lenguas europeas que no pertenece al grupo de las indoeuropeas; y la historia se vinculaba con la vigencia y abolición de los Fueros -las leyes que habían regido al País Vasco a lo largo de su historia- (Álvarez Gila y Tápiz Fernández, 1996: 235-236). Estos elementos y su tratamiento eran recurrentes en los artículos de Euzko Deya, aunque con variable peso, según el autor y el tema abordado. Su presencia y continuidad a lo largo de los años analizados permite descubrir que fueron factores clave en la conformación de una imagen del País Vasco, a través de Euzko Deya.

Dicha identidad remitía en todo momento a un cuerpo colectivo, a un "nosotros" y no a una identificación individual y personal (Douglass y Totoricaguena, 1999: 264). Euzko Deya asumió la responsabilidad de "preservar el buen nombre de los vascos". El mantenimiento de esa "etnicidad" entre los exiliados vascos se tornó una cuestión fundamental: era importante resguardar la buena consideración que gozaban los vascos en la Argentina (Ortuño Martínez, 2011: 168) y Euzko Deya se propuso trabajar para ello a lo largo de toda su existencia.

\section{Las relaciones con la comunidad emigrada}

El reforzamiento de los elementos identitarios del pueblo vasco conllevó un acercamiento progresivo de Euzko Deya al tejido institucional de la comunidad vasca emigrada en la Argentina, y a sus más destacadas 
personalidades. En su número segundo, Euzko Deya inauguró una sección titulada "Notas de la colectividad" (1939: 6), destinada a reflejar la vida social y cultural de los vascos y sus entidades representativas en el país austral. De este modo, se creó un espacio dentro del periódico para la transmisión de las noticias inherentes al funcionamiento de los centros, sociedades y organismos vascos en Argentina -más tarde incluiría también a los localizados en Chile o en Uruguay-, tales como la realización de asambleas y reuniones estatutarias, la organización de fiestas y festivales, la celebración de misas, funciones teatrales o corales, entre otras.

En la citada sección se hacía referencia a las instituciones creadas por los inmigrantes vascos arribados antes del desencadenamiento de la Guerra Civil en España (como el Laurak Bat de Buenos Aires, el Zazpirak-Bat de Rosario o el Euskal Echea de Lavallol, entre los principales), que poseía conducciones que defendían el nacionalismo vasco o eran proclives al mismo, como ya anticipamos. Euzko Deya retomaba con ello una modalidad característica de los periódicos españoles de la emigración (ya sea los representativos de una identidad nacional, regional o microrregional), tendiente a dar conocer los principales hitos en el desenvolvimiento del movimiento asociativo en el cual se referenciaban. De esta forma, al difundir las noticias ligadas a la vida institucional de la comunidad vasca emigrada en la Argentina, Euzko Deya no solo buscaba atraer su interés y atención, sino que también intentaba legitimarse ante ella, al mostrarse como un medio de comunicación que no solo se preocupaba por la problemática del exilio vasco, sino también de los emigrantes económicos en un sentido más estricto.

Sin embargo, la sección titulada "Notas de la colectividad" también llegó a reflejar algunas noticias sobre los refugiados vascos, como cuando se informó de la llegada del Vapor "Massilia” a la Dársena Norte, el 5 de noviembre de 1939, con un nutrido contingente de artistas y profesionales exiliados, muchos de ellos de origen vasco. Estos últimos fueron recibidos por la Secretaría de la Liga de los Amigos de los Vascos, que contribuyó a orientarlos y asistirlos en las tramitaciones iniciales en suelo argentino (“Numerosos vascos...”, 1939: 8). La visión de estos hechos, por parte de Euzko Deya, era la de una gesta heroica protagonizada por quienes, pese a los evidentes situaciones traumáticas vividas, se comportaban como sobrevivientes agradecidos y dispuestos a adaptarse armoniosamente al medio de acogida.

Además de interesarse por las instituciones, migrantes y refugiados vascos, Euzko Deya propició la participación en sus páginas de algunos peninsulares que podían oficiar como intermediadores con la sociedad 
argentina. Tal fue el caso de Amado Alonso, quien nacido en Navarra y formado en España en las letras y humanidades, fue uno de los tantos colaboradores de Euzko Deya. Alonso había llegado a la Argentina en 1927 y para 1939 se encontraba dirigiendo el Instituto de Filología de la Facultad de Filosofía y Letras de la Universidad de Buenos Aires. Gozaba de un importante reconocimiento y prestigio académico dentro del país austral. Sus palabras a favor del auxilio a los refugiados en el primer número del periódico apuntaron a respaldar la creación de la sección argentina de la Liga Internacional de Amigos de los Vascos, la que contaba con la participación de destacados representantes del catolicismo europeo (Alonso, 1939a: 5). La intervención de Alonso permitía poner al descubierto que no solo los vascos eran católicos, sino que distintas instituciones católicas los apoyaban, lo que autorizaba a Euzko Deya a aclarar que ese catolicismo no era el mismo catolicismo que había apoyado a Franco. En agosto de 1939 el Instituto de Filología invitó al euskerólogo capuchino P. Bonifacio de Ataun a dictar unas seis conferencias sobre filología vasca, que también fueron promovidas por Euzko Deya, en el marco de su importante vinculación con Alonso y como parte de su política de reforzamiento del nacionalismo vasco en la Argentina ("El euskera en la Universidad Argentina”, 1939: 3).

\section{Concepciones y roles esperables de las mujeres}

Para Euzko Deya, las mujeres estaban llamadas a tener un rol destacado en la reconstrucción del pueblo vasco, no precisamente a través de la palabra escrita como articulistas, sino mediante el desarrollo de labores asistenciales. Ya habían dado muestras de una participación comprometida a través de la constitución de emakumes (organizaciones femeninas conformadas en Euzkadi durante la Guerra Civil), que encontraron su reflejo en el surgimiento de similares organizaciones en Buenos Aires, Rosario o Santiago de Chile, denominadas oficialmente Emakume Abertzale Batza. En mayo de 1939, Euzko Deya anunciaba y apoyaba los propósitos por los cuales se originaron las entidades de Buenos Aires y Rosario ("La obra del amor...", 1939: 8) y luego se ocupó de informar sus acciones y actividades. En octubre de 1939 difundió los estatutos de la homónima de Santiago de Chile, cuyos objetivos principales coincidían con los de las instituciones de su tipo en la Argentina ("Estatutos...", 1939: 3). La Emakume Abertzale Batza porteña, nacida en agosto de 1938, dio a conocer su programa y sus memorias en Nación Vasca, el órgano vocero de la Acción Nacionalista Vasca a la cual adhería. Entre los objetivos que se proponía alcanzar la última Emakume Abertzale Batza mencionada, se encontraban los siguientes: 

A. Establecer vínculos de relación espiritual entre las asociadas.
B. Difundir las características del pueblo vasco, dando a conocer las manifestaciones del arte, su literatura, música, bailes, etc.
C. Ayudar a las familias expatriadas que lleguen a este país.
D. Arbitrar recursos para las emakumes que en estos momentos sufren en el extranjero, la amargura del exilio forzoso creado por la guerra.
E. Colaborar en toda iniciativa que propenda a la elevación moral y cultural de Euzkadi y la de nuestra colectividad en la Argentina (“Emakume Abertzale Batza”, 1939: 6).

De estos postulados, la Emakume Abertzale Batza de Buenos Aires se abocó principalmente a la recaudación de dinero y donativos para las mujeres y niños exiliados en Francia, apelando a los sentimientos de "caridad cristiana" y "fraternidad racial" de los contribuyentes. Para ello, se organizaron fiestas benéficas que eran promocionadas por Euzko Deya, en la sección "Notas de la colectividad".

Recordemos que dentro de la Argentina los niños huérfanos españoles de la Guerra Civil habían concitado la atención y preocupación de diversos organismos que fueron creados para socorrerlos. Tanto los sectores republicanos como los pro-franquistas generaron agrupaciones destinadas a asistir económicamente a la infancia huérfana de uno y otro bando, o a trasladarla y darle acogida en el país sudamericano, con distintos resultados y grados de efectividad. Algunas de esas iniciativas emanaron de la sociedad civil y otras de la comunidad española establecida en el país austral. Dentro de esta última, y a favor de los niños huérfanos del bando republicano, se crearon algunas instituciones como la Agrupación Femenina pro Infancia Española del Centro Republicano Español de Buenos Aires y la Asociación Gallega Femenina de Ayuda a los Huérfanos Españoles (Moreno Seco y Ortuño Martínez, 2013: 185). Estas últimas, junto a las Emakume Abertzale Batza de Buenos Aires y Rosario compartieron un rasgo importante: el hecho de favorecer una novedosa participación de las mujeres en el espacio público, con cierta independencia de los hombres, aunque ello no implicara romper con los roles que tradicionalmente les eran asignados en el ámbito doméstico (como el cuidado y la protección maternal, por ejemplo) (Moreno Seco y Ortuño Martínez, 2013: 186; Vitullo, 2012: 55).

\section{Las claves del apoyo a la legalidad republicana}

Euzko Deya fue una herramienta de la Delegación del Gobierno Vasco en Sudamérica y como tal, encarnó a lo largo de sus páginas los postulados 
que tempranamente, desde 1936, el Gobierno Vasco había mantenido en relación con su política exterior: a) la vinculación orgánica con la presidencia -expresada en el importante peso otorgado a la llegada de Aguirre a América y a sus propósitos de conducción política de la "diáspora" vasca-; b) la concientización sobre los problemas de Euskadi, el valor de la democracia como forma de organización política y social, y el rechazo a la dictadura franquista; c) la necesidad de mantener las relaciones con las comunidades vascas emigradas y de dotarlas de un fuerte sentimiento identitario; d) el auxilio a los grupos de exiliados, especialmente los que estaban localizados en Francia y serían perjudicados por el inicio y desarrollo de la Segunda Guerra Mundial (Sanz Goikoetxea y Álvarez Gila, 2010b: 107-108).

Tengamos presente que desde Euzko Deya la campaña para sensibilizar a los lectores sobre la grave situación de los exiliados fue muy profusa e involucró acciones concretas encaminadas a recaudar fondos para atender las necesidades de los huérfanos, viudas y refugiados en Francia, como por ejemplo, la publicidad de los cigarrillos Leales (con cuyas ventas se reunía dinero para el auxilio de los exiliados), o la difusión de las iniciativas de recaudación de fondos y donativos de las emakumes, a las que ya nos referimos.

En la medida en que Euzko Deya era portavoz de los intereses del Gobierno Vasco y especialmente, del Partido Nacionalista Vasco, reveló en sus páginas los móviles centrales del apoyo del último al bando republicano: no fue la defensa de los postulados republicanos lo que habían conducido a los vascos a posicionarse del lado de la legalidad republicana, pese a compartir el antifascismo del Frente Popular, sino la búsqueda de la puesta en marcha del Estatuto de Autonomía, que solo podía ser garantizada en el marco de la República (Núñez Seixas, 2007: 6). De allí que para Euzko Deya fuera clave salvaguardar los fundamentos del Estatuto de Autonomía vasco, lo que implicaba ubicarse ideológicamente en las antípodas del régimen de Franco. El periódico en cuestión se convirtió de este modo en uno de los referentes de la oposición nacionalista vasca al franquismo, lo que permitió al Gobierno Vasco mantener una imagen de activismo político en su etapa de exilio en París y luego de la misma, una vez iniciada la invasión de Francia por los alemanes en mayo de 1940.

\section{Conclusiones}

El 10 de mayo de 1941, cuando se cumplían dos años de la publicación del primer número de Euzko Deya, el balance que hacía este último de su cometido era ambiguo: por un lado, enfatizaba y explicaba minuciosamente 
los logros alcanzados tras una entusiasta gestión destinada a estimular las vinculaciones de solidaridad y cordialidad de las entidades vascas en la Argentina, la asistencia a los vascos exiliados en Europa y el enaltecimiento de la cultura e idiosincrasia vascas (con la creación de coros, grupos de bailes, ediciones de libros sobre gramática euskera o sobre la historia del pueblo vasco, entre otros aspectos). Pero por otro lado, el órgano en consideración hacía un llamamiento a que los vascos instalados en el país austral contribuyeran económicamente, según sus disponibilidades personales, con la tarea desarrollaba por la Liga de los Amigos de los Vascos en la Argentina, en momentos en que los gastos de la misma eran crecientes, apremiantes e impostergables ("Resumen de dos años de labor...", 1941: 1-2). Euzko Deya planteaba que era inadmisible que este esfuerzo monetario recayera únicamente en los miembros del Comité Pro-Inmigración Vasca, quizás en parte porque recelaba el alcance político que había logrado este último. La publicación de notas de algunos vascos y grupos de vascos dispuestos a donar distintas sumas de dinero para la causa defendida por Euzko Deya, en el mismo número aniversario, intentaba dar cuenta públicamente de la importante resonancia que había tenido el mensaje del periódico, dentro de la comunidad vasca en la Argentina.

Creemos que a partir de nuestra indagación, focalizada en un periódico del exilio nacionalista vasco en la Argentina, se puede contribuir al conocimiento del desarrollo y alcances de la prensa del exilio español en el continente americano. Tema este último mucho más abarcativo y complejo que el aquí presentado, cuya comprensión requiere, desde nuestro punto de vista, un trabajo en distintas etapas: una primera abocada a análisis preliminares de emprendimientos periodísticos particulares, y una segunda, en la cual a partir de los estudios específicos, se apunte a la reconstrucción de un panorama de la prensa en los distintos países americanos en su conjunto, desde enfoques comparativos y críticos.

Los estudios del activismo político desde la prensa de la comunidad española en el continente americano, durante la Guerra Civil y el primer franquismo, van revelando el heterogéneo universo de publicaciones que fueron politizadas o surgieron con fines político-propagandísticos, en dichas años: desde aquellas que eran voceras de distintos tipos de instituciones, hasta otras que eran producto de iniciativas particulares; desde las que pertenecían al entramado asociativo de las comunidades emigradas previas a la Guerra Civil, hasta las que fueron surgiendo a lo largo de la misma; desde las que se identificaban con la nación española en su conjunto, hasta aquellas otras que se referenciaban en entidades políticas, administrativas o socio-culturales menores, como las regiones o los municipios hispánicos. Es posible que a partir de indagaciones centradas en casos de periódicos 
específicos, se pueda avanzar también en una tipología más completa y precisa de la prensa politizada americana, ligada a la evolución española durante la Guerra Civil y el régimen franquista. Tal vez ello nos permita superar la tradicional (y un tanto simplificada) divisoria que ha operado en la historiografía sobre el tema, entre la prensa que apoyaba al franquismo y la que se mantenía a favor de la legalidad republicana.

Visto desde la América del Sur, el $1^{0}$ de abril de 1939 tuvo un sentido ambivalente para muchos sectores de la comunidad española allí instalada: para los pro-franquistas la contienda había terminado y había que iniciar una etapa de reconciliación entre los bandos otrora enfrentados, la que se seguiría de la posterior rehabilitación del franquismo (Ferreyra, 2018). Pero sin embargo, los debates sobre el futuro de España y sobre la legitimidad del franquismo en tanto régimen, así como las expectativas de la reinstauración de la República, permanecieron abiertos para muchos miembros de la comunidad hispánica y para determinados círculos de intelectuales y políticos de la sociedad local sudamericana. Asimismo, las consecuencias de la Guerra Civil se prolongaron en la Argentina en fenómenos palpables y visibles, tales como la llegada de una continua corriente de exiliados, que incluso fue más cuantiosa que la producida entre el inicio y fin de la Guerra Civil. ${ }^{8}$

Para quienes habían permanecido fieles a la legalidad republicana (por motivos diversos) la Guerra Civil no había terminado en abril de 1939. El caso de los vascos nacionalistas ilustra lo afirmado: para ellos la contienda iba a finalizar cuando se le restituyeran las libertades al pueblo vasco . De este modo, las definiciones políticas inconclusas los autorizaban a concebir a la guerra como inacabada. Además, la esperanza del retorno a la tierra de origen -sentimiento de peso variable a lo largo de la Segunda Guerra Mundial, pero en líneas generales, presente durante todo su desarrolloalimentaba dentro de la comunidad española exiliada el mantenimiento de identidades y lealtades nacionales, regionales, político-culturales propias de la etapa bélica e incluso pre-bélica, pero en suelo americano, lo que también dotó al período posterior al $1^{\circ}$ de abril de 1939 de una fuerte continuidad con el previo.

8 Ortuño Martínez (2018: 43) diferenció tres etapas en el exilio republicano español hacia la Argentina: la primera de 1936 a 1938, la segunda desde 1939 a 1945, y la tercera desde 1946 a 1956. Dentro de la segunda fase distinguió dos sub-periodos: 1939-1942 (cuando se produjo el mayor número de llegadas de exiliados al país austral) y 1943-1945 (cuando los arribos ya fueron más puntuales, debido a la evolución de la Segunda Guerra Mundial). 
Por último, para una gran parte del exilio vasco en la Argentina algunos rasgos de la Guerra Civil se prolongaban en la Segunda Guerra Mundial: los ataques alemanes contra la ciudad polaca de Czestochowska, al inicio de la Segunda Guerra en 1939, no eran algo novedoso en la mirada de Euzko Deya, sino que se inscribían en un continuum de lógicas agresivas alemanas que ya se habían puesto en marcha en las destrucciones aéreas de Durango o Guernica, en 1937, en el País Vasco. De modo que el periódico contribuía a reforzar la imagen de la Guerra Civil como una primera etapa o campo de ensayo de la embestida alemana, y también más extensamente de los "totalitarismos", los cuales llegarían a su fase de máxima expansión durante la Segunda Guerra Mundial ("Nuestro dolor ante la Guerra”, 1939: 1).

En su análisis sobre la construcción identitaria de la diáspora vasca en el Río de la Plata, Álvarez Gila (2016) distinguió entre el “colectivo” y la "colectividad" de los inmigrantes vascos, entendiendo al primero como todos aquellos que se radicaron en un país de acogida determinado, y a la segunda como "la parte del colectivo que genera un discurso sobre su propio ser y se define como mediador entre el colectivo y la sociedad de acogida, modulando y usufructuando los elementos de imagen, representación y representatividad de la totalidad" (pp. 80-81).

Si seguimos estas nociones y entendemos a la "colectividad" como un concepto "social-representativo" y al "colectivo" como una noción "demográfica-cuantitativa”, podríamos afirmar que Euzko Deya surgió en el seno de la colectividad de exiliados en Buenos Aires, pero buscó erigirse en vocera de los vascos (entendido este grupo como el colectivo conformado por emigrados y exiliados) en el continente americano. Intentó adquirir representatividad entre los vascos que se identificaban con la definición política del Estatuto de Autonomía de 1936. Para ello apeló a reforzar ciertos elementos identitarios entre su público lector, al tiempo que afianzó o generó vínculos con distintos tipos de interlocutores de la comunidad hispánica o de la sociedad argentina, que contribuyeron de distintos modos con la consecución de sus objetivos políticos. 


\section{Q Bibliografía}

»Alonso, A. (10/05/1939a). La Liga Internacional de Amigos de Euzkadi. Euzko Deya. La voz de los vascos en América (en adelante: Euzko Deya), Año 1, 1, 5 .

"Alonso, A. (30/06/1939b). Los vascos y el mundo católico. Euzko Deya, Año $1,6,1$.

»Alonso Carballés, J. J. (2007). El primer exilio de los vascos, 1936-1939, Historia Contemporánea, 35, 683-708. https://www.ehu.eus/ojs/index.php/ HC/article/view/4117/3667

»Álvarez Gila, Ó. (2016). De una inmigración regional a una colectividad nacional. Imagen y procesos en la construcción identitaria de la diáspora vasca en el Río de la Plata. RiMe, 17/1, 63-85.

»Álvarez Gila, Ó. (2019). Entre la información y la creación de identidad: origen y desarrollo de la prensa de la emigración vasca en América, 18771936, RIHC: Revista Internacional de Historia de la Comunicación, 12, 16-40. https://doi.org/10.12795/RiHC.2019.i12.02

» Álvarez Gila, Ó. y Tápiz Fernández, J. M. (1996). Prensa nacionalista vasca y emigración a América (1900-1936), Anuario de Estudios Americanos, 53(1), 233-260. estudiosamericanos.revistas.csic.es/index.php/ estudiosamericanos/article/view/440/446

»Bergareche, M. (2009). El ser vasco en un país lejano. Identidad e integración. La Vasconia (1893-1914). Temas de Historia Argentina y Americana, 15, 1551. https://repositorio.uca.edu.ar/handle/123456789/7606

"Con motivo de un decreto del Poder Ejecutivo (02/1940). Galicia. Revista del Centro Gallego, Año XXVII, 325, 9-10.

»Comité Pro-Inmigración Vasca (30/08/1939). Euzko Deya, Año 1, 12, 5.

»Con la boina en la mano (10/05/1939). Euzko Deya, Año 1, 1, 1-2.

»Cruset, M. E. (2011). Migración transnacional: la diáspora vasca en Argentina como agente de para-diplomacia. Relaciones Internacionales, 20(40), s./p. https://revistas.unlp.edu.ar/RRII-IRI/article/view/1217

»Cuarto Censo General de la Ciudad de Buenos Aires (1936). Buenos Aires: Municipalidad de la Ciudad de Buenos Aires, T. II.

»Chueca Intxusta, J. (2011). La Guerra Civil a través de las publicaciones vascas en el exilio franco americano. Amnis. Revue de civilisation contemporaine Europes/Amériques, 2, s./p. https://doi.org/10.4000/ amnis.1494

»De Cristóforis, N. (2019). "La prensa gallega de Buenos Aires y su apoyo al franquismo: estrategias propagandísticas y activismo político", RIHC: Revista Internacional de Historia de la Comunicación, 12, 178-200. http:// dx.doi.org/10.12795/RiHC.2019.i12.09

»De Cristóforis, N. y Cócaro, P. (2011). A Dirección Xeral de Inmigración e o ingreso dos exiliados españois na Arxentina. En N. De Cristóforis (Coord.), 
Baixo o signo do franquismo: emigrantes e exiliados galegos na Arxentina (pp. 79-109). Santiago de Compostela: Sotelo Blanco Edicións.

»Devoto, F. (2001). El revés de la trama: políticas migratorias y prácticas administrativas en la Argentina (1919-1949). Desarrollo Económico, 41(162), 281-304.

»Douglass, W. A. y Totoricaguena, G. (1999). Identidades complementarias. La sociabilidad y la identidad vascas en la Argentina entre el pasado y el presente. En A. E. Fernández \& J. C. Moya (Eds.), La inmigración española en la Argentina (pp. 257-271). Buenos Aires: Biblos.

»Efemérides argentinas del mes (10/05/1939). Euzko Deya, Año 1, 1, 6.

» 'El Atlántico' de Bahía Blanca y los vascos (20/05/1939). Euzko Deya, Año $1,2,8$.

»El euskera en la Universidad Argentina (30/08/1939). Euzko Deya, Año 1, $12,3$.

»El presidente Pellegrini y su admiración por los vascos (20/12/1939). Euzko Deya, Año 1, 23, 8.

»Emakume Abertzale Batza (08/1939). Nación Vasca. Órgano de Acción Vasca, de la Argentina, Año XVI, 106, 6.

"Estatutos de la Emakume Abertzale Batza de Santiago de Chile (10/10/1939). Euzko Deya, Año 1, 16, 3.

»Homenaje a la Bandera (20/06/1939). Euzko Deya, Año 1, 5, 1.

»Euzko Deya (20/01/1940a). Año 2, 26, 1.

»Euzko Deya (20/07/1940b). Año 2, 44, 1.

»Fasano, L. (2010). Exiliados republicanos en la Federación de Sociedades Gallegas de la Argentina: una aproximación al tema. Estudios Migratorios Latinoamericanos, 24(69), 371-387.

»Fasano, L. (2014). Los exiliados republicanos y sus vinculaciones con el movimiento asociativo étnico: el caso de la Federación de Sociedades Gallegas de la Argentina. En M. C. Bravo \& S. Fernández (Comps.), Formando el espacio público: Asociacionismo y política, s. XIX y XX (pp. 159-180). Tucumán: EDUNT.

"Fernández, A. (2010). La revista Catalunya de Buenos Aires, el exilio y la colectividad inmigrada(1927-1964), Estudios Migratorios Latinoamericanos, 69, 389-412.

»Fernández, A. (2019). Los catalanes y Buenos Aires. Inmigración, asociaciones y prensa. Buenos Aires: Almaluz.

»Ferreyra, A. (2018). La conformación de un consenso pro-franquista en la comunidad española de Buenos Aires: solidaridad material y propaganda político-cultural (1936-1945). Tesis doctoral inédita. Buenos Aires: Facultad de Filosofía y Letras, Universidad de Buenos Aires.

"Irianni, Marcelino (2010). Historia de los vascos en la Argentina. Buenos Aires: Biblos.

"La obra del amor. Emakumes en la Argentina (10/05/1939). Euzko Deya, Año 1, 1, 8. 
»Liga de los Amigos de los Vascos (10/10/1939). Euzko Deya, Año 1, 16, 8.

"Lo que los no vascos piensan de los vascos (20/06/1939). Euzko Deya, Año 1, 5, 2.

»Los vascos en la independencia argentina (20/05/1939). Euzko Deya, Año $1,2,1$.

»Los Vascos y los Comunistas (10/09/1939). Euzko Deya, Año 1, 13, 2.

"Lucci, M. (2020). El "seny" y la "rauxa" de la revista Ressorgiment durante la guerra civil española. Los "catalanes de América" de Buenos Aires y la defensa de la II República desde el exilio (1936-1939). En N. De Cristóforis (Dir.). Los españoles en Buenos Aires: activismo político e inserción sociocultural (1870-1960) (pp. 233-278). Buenos Aires: Teseo.

"Llamamiento a los vascos y simpatizantes de los vascos (20/10/1939). Euzko Deya, Año 1, 17, 8.

»Mauriac, F. (10/05/1939). La victoria de los vascos. Euzko Deya, Año 1, 1, 6.

»Moreno Seco, M. y Ortuño Martínez, B. (2013). Exiliadas españolas en Francia y Argentina: identidades transnacionales y transferencias culturales, Storia delle donne, 9, s./p. http://fupress.net/index.php/sdd

»Mota Zurdo, D. (2018). "La lucha por la libertad". El Gobierno vasco en el exilio y sus colectividades a través de las ediciones americanas de Euzko Deya (1939-1953). RIHC: Revista Internacional de Historia de la Comunicación, 11, 102-125. http://dx.doi.org/10.12795/RiHC.2018.i11.07

» Moya, J. C. (2004). Primos y extranjeros. La inmigración española en Buenos Aires, 1850-1930. Buenos Aires: Emecé.

»Notas de la colectividad (20/05/1939). Euzko Deya, Año 1, 2, 6.

»Nuestro dolor ante la Guerra (10/09/1939). Euzko Deya, Año 1, 13, 1.

"Numerosos vascos Ilegaron en el "Massilia" (10/11/1939). Euzko Deya, Año 1, 19, 8.

»Núñez Seixas, X. M. (2007). Los nacionalistas vascos durante la Guerra Civil (1936-1939): una cultura de guerra diferente. Historia Contemporánea, 35, 559-599. https://www.ehu.eus/ojs/index.php/HC/article/view/4109

" Ortuño Martínez, B. (2011). Del casino al centro: el exilio republicano y el asociacionismo español en América. Historia Social, 70, 155-173.

» Ortuño Martínez, B. (2018). Hacia el hondo bajo fondo... Inmigrantes y exiliados en Buenos Aires tras la Guerra Civil española. Madrid: Biblioteca Nueva.

» Reafirmación de la personalidad vasca (20/06/1939). Euzko Deya, Año 1, $5,1-2$.

»Resumen de dos años de labor al servicio de los nobles ideales de la Liga de Amigos de los Vascos (10/05/1941). Euzko Deya, Año 3, 73, 1-2.

»Sanz Goikoetxea, E. y Álvarez Gila, Ó. (2010a). Las Delegaciones en ultramar. En Delegaciones de Euskadi (1936-1975). Antecedentes históricos de los siglos XVI al XIX, origen y desarrollo (pp. 155-276). Donostia/San Sebastián, Servicio Central de Publicaciones del País Vasco.

»Sanz Goikoetxea, E. y Álvarez Gila, Ó. (2010b). Entre dos guerras: 1936- 
1940. En Delegaciones de Euskadi (1936-1975). Antecedentes históricos de los siglos XVI al XIX, origen y desarrollo (pp. 99-152). Donostia/San Sebastián, Servicio Central de Publicaciones del País Vasco.

"Schwarzstein, D. (2001). Entre Franco y Perón. Memoria e identidad del exilio republicano español en Argentina. Barcelona: Crítica.

» Tercer Censo Nacional, T. II, Población. (1916). Buenos Aires.

»Vitullo, M. (2011). La ayuda a los exiliados vascos en la génesis argentina de Emakume Abertzale Batza. (1938-1943). Migraciones \& Exilios: Cuadernos de la Asociación para el estudio de los exilios y migraciones ibéricos contemporáneos, 12, 49-61. 
